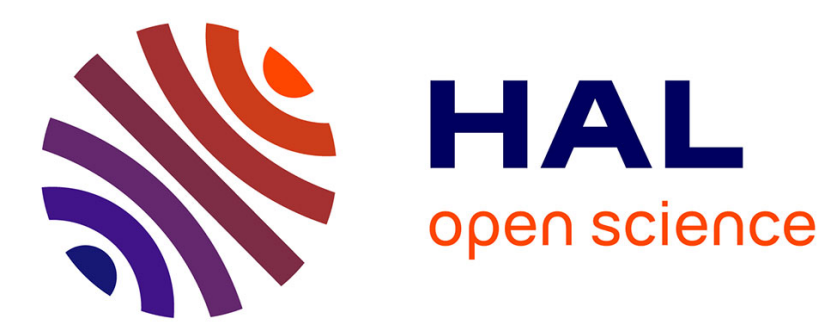

\title{
Investment, Adverse Selection and Optimal Redistributive Taxation
}

Anastasios Dosis

\section{To cite this version:}

Anastasios Dosis. Investment, Adverse Selection and Optimal Redistributive Taxation. 2016. hal01285163

\section{HAL Id: hal-01285163 \\ https://essec.hal.science/hal-01285163}

Preprint submitted on 9 Mar 2016

HAL is a multi-disciplinary open access archive for the deposit and dissemination of scientific research documents, whether they are published or not. The documents may come from teaching and research institutions in France or abroad, or from public or private research centers.
L'archive ouverte pluridisciplinaire HAL, est destinée au dépôt et à la diffusion de documents scientifiques de niveau recherche, publiés ou non, émanant des établissements d'enseignement et de recherche français ou étrangers, des laboratoires publics ou privés. 


\title{
E \\ ESS EC \\ BUSINESS SCHOOL
}

INVESTMENT, ADVERSE SELECTION AND OPTIMAL REDISTRIBUTIVE TAXATION

\author{
RESEARCH CENTER \\ ESSEC WORKING PAPER 1605
}

2016

Anastasios Dosis 


\title{
Investment, Adverse Selection and Optimal Redistributive Taxation
}

\author{
Anastasios Dosis*
}

February 17, 2016

\begin{abstract}
I study a credit market with adverse selection as a signalling game. I show that in the least-costly separating equilibrium, entrepreneurs of high-quality projects may over- or under-invest compared to the social optimum to signal their type. I then examine a simple budget-balanced tax-subsidy scheme applied by the government. At a first sight, the tax-subsidy scheme seems to benefit entrepreneurs of low-quality projects and harm entrepreneurs of high-quality projects because the former are crosssubsidised by the latter. Nonetheless, this result does not necessarily hold if entrepreneurs can pledge the subsidy as collateral. In that case, taxes can improve social welfare by either decreasing or increasing aggregate investment depending on whether entrepreneurs of high-quality projects over- or under-invest in equilibrium.
\end{abstract}

KEYWORDS: Adverse selection, investment, taxes, welfare

JEL CLASSIFICATION: D04, D60, D82, D86, H25, H82

\section{INTRODUCTION}

- Motivation. It is a well-known fact that adverse selection causes inefficiencies in markets that frequently justify for government intervention. For instance, as shown in Wilson (1977), Dahlby (1981) and Crocker and Snow (1985a,1985b), a simple budgetbalanced tax-subsidy scheme can improve the welfare of all consumers in a stylised insurance market. In this paper, I examine under what conditions this argument extends to credit markets.

In particular, I analyse a credit market with cashless entrepreneurs and wealthy investors. Entrepreneurs own uncertain, variable investment projects that can be either of

${ }^{*}$ Department of Economics - ESSEC Business School and THEMA, 3 Avenue Bernard Hirsch, 95021 Cergy-Pontoise Cedex, France, Email: dosis@essec.com. I have greatly benefited from discussions with Theo Diasakos, Peter Hammond, Motty Perry, Herakles Polemarchakis and Phil Reny. I would also like to thank an anonymous referee and an associate editor whose suggestions significantly improved the paper and forced me to generalise and simplify the results. All the remaining errors are mine. 
high or low quality. The quality of the project is only known by the entrepreneur who owns it. Investors are willing to lend funds to entrepreneurs but are unable to observe the actual type of the project they get to finance, which leads to an adverse selection problem as in Akerlof (1970). Nonetheless, entrepreneurs can partially, or fully, transmit their information using as sorting devices the amount of loan and a share from the return of the project. Therefore, a signaling problem arises as in Spence (1973) and Rothschild and Stiglitz (1976). I characterise the set of perfect Bayesian equilibria (PBE) of a game in which each entrepreneur proposes a loan contract to a single representative investor who accepts or rejects. ${ }^{1}$ Perhaps as expected, I show that the only PBE that passes the intuitive criterion of Cho and Kreps (1987) is the least-costly separating one. Depending on parameter values, this equilibrium is characterised by under- or over-investment compared to the social optimum. In particular, if the high-quality project first-order stochastically dominates (FOSD) the low-quality one, then over-investment is possible. On the contrary, in the case of second-order stochastic dominance (SOSD), under-investment is possible. ${ }^{2}$

Subsequently, I examine the impact of a simple tax-subsidy scheme on the equilibrium aggregate investment and welfare. The tax system I consider is similar to the one discussed in Wilson (1977), Dahlby (1981) and Crocker and Snow $(1985,1986)$ in the stylised insurance market of Rothschild and Stiglitz (1976), and more recently in Ghatak et al. (2007) and Scheuer (2013) in a credit market. I establish that, depending on parameter values, the government can increase, or decrease, aggregate investment ex ante and create Pareto improvements through this simple redistributive tax system. A necessary condition for this result is that entrepreneurs be allowed to make their contracts contingent on the subsidy they receive from the government. Evidently, this does neither require the government to possess superior information than the investor nor, to provide any additional financing for entrepreneurs at the time of contracting. The only intervention takes place after the realisation of uncertainty in the form of redistribution of wealth.

To explain the mechanism that drives the result note that the tax scheme clearly benefits entrepreneurs of low-quality projects because they are cross-subsidised from entrepreneurs of high-quality projects. On the contrary, for entrepreneurs of high-quality projects, there are two opposite effects. On the one hand, there is the negative crosssubsidisation effect stated above. On the other hand, the use of the subsidy in the equilibrium contract relaxes the incentive constraint of entrepreneurs of low-quality projects and hence allows entrepreneurs of high-quality projects to move closer to the first-best level of investment. In some cases, the latter effect dominates the former and consequently all entrepreneurs benefit from the tax system.

Perhaps interestingly, the impact of taxation on aggregate investment depends on how the projects of the two types of entrepreneurs are related. In the case of FOSD, aggregate investment is strictly decreasing in taxes, because in that case over-investment results

\footnotetext{
${ }^{1}$ The use of a single investor is only for simplicity. Adding more investors increases the notational burden without changing the qualitative features of the results.

${ }^{2}$ Interestingly, in models with fixed investment projects, Stiglitz and Weiss (1981) show that when returns are ranked in an SOSD sense, there is credit rationing in equilibrium, i.e. under-investment, whereas De Meza and Webb (1987) show that when returns are ranked in an FOSD sense, there is over-investment in equilibrium.
} 
in equilibrium. Hence, a lower level of aggregate investment benefits entrepreneurs of high-quality projects as well as it is socially desirable. An increase in taxation reduces aggregate investment and brings the economy closer to the first-best. The opposite result prevails in the case of SOSD.

Related Literature. Regarding the related literature, the inefficiency of competitive equilibrium in markets with adverse selection and non-linear pricing dates back to Spence (1973) and Rothschild and Stiglitz (1976). Spence (1973) assumes that the price of education is determined by the competitive market mechanism and workers only decide how much education to acquire. He establishes that a plethora of equilibria can be sustained that involve or do not involve signaling. On the contrary, Rothschild and Stiglitz (1976) assume that the uninformed parties in the market compete by offering contracts to informed consumers. Each uninformed party can only offer a single contract. Miyazaki (1977) shows that the equilibrium of Rothschild and Stiglitz (1976), when this exists, might be inefficient because efficiency might require cross-subsidisation that is artificially excluded in Rothschild and Stiglitz (1976). Miyazaki (1977) and Spence (1978) allow the informed parties to offer menus of contracts, by adopting at the same time the E2 equilibrium of Wilson (1977) and show that efficiency is restored.

As I mentioned above, a similar tax-subsidy scheme is considered in Wilson (1977), Dahlby (1981) and Crocker and Snow (1985a,1985b) in a stylised model of an insurance market, and in Ghatak et al. (2007) and Scheuer (2013) in a model of occupational choice and adverse selection in the credit market. Ghatak et al. (2007) and Scheuer (2013) consider a model in which an individual can select between becoming a worker, and receive the labour market wage, or an entrepreneur, and borrow from the credit market. The tax-subsidy scheme aims to discourage low-quality individuals to become entrepreneurs to "correct" for occupational choice by reducing adverse selection and hence improve efficiency. In this paper, I allow for variable investment projects as opposed to fixedinvestment projects, which allows for signaling in equilibrium. Moreover, I consider both FOSD and SOSD. Lastly, the subsidy received by the government plays a fundamental role in this paper since a necessary condition to improve over the market outcome is for entrepreneurs to be allowed to pledge the subsidy as collateral.

Two strands in the literature consider efficiency in competitive markets with adverse selection. First, Bisin and Gottardi (2006) show how, in the Rothschild and Stiglitz (1976) canonical insurance market, the establishment of a market for property rights can relax the incentive constraints and help the economy attain Pareto efficiency. In a similar spirit, Martin (2011) shows that in a credit market with adverse selection the government, by establishing a new market at the ex ante stage in which entrepreneurs can borrow without conditioning their loans, Pareto efficiency can be attained. ${ }^{3}$ Equally related is the contribution by Innes (1991) who shows how the government can increase social welfare by offering subsidised debt contracts ex ante in a credit markets with adverse selection. Martin (2011) and Innes (1991) should be considered as complementary to this paper. The main

\footnotetext{
${ }^{3}$ Martin (2011) builds on Martin (2009) who shows how entrepreneurial wealth affects economy's aggregate investment.
} 
difference is on the type of intervention. In Martin (2011) and Innes (1991), government interventions occur ex ante (where investment decisions take place) in the form of creation of a new lending market regulated by the government or through subsidised debt contracts. On the contrary, in this paper, the government intervention occurs ex post (when entrepreneurs have realised their returns) in the form of taxation. Second, a relatively recent literature examines different than Rothschild and Stiglitz (1976) games of competition for contracts. Contributions in that literature are Asheim and Nilssen (1996), Diasakos and Koufopoulos (2011), Mimra and Wambach (2011), Netzer and Scheuer (2014), Picard (2014) and Dosis (2015). This literature either draws insights from the notion of equilibrium of Wilson (1977) by allowing insurance companies to withdraw contracts they have offered in the market when these become loss-making or construct different, more complex games to reduce the set of profitable deviations of insurance companies. This paper differs from all those mentioned above because it assumes a simpler form of trade of loan contracts. In particular, it assumes that entrepreneurs apply for loan contracts to a representative investor who decides whether to accept or reject. This model of trade is closer in spirit to the signalling model initially studied by Spence (1973). There are at least two reasons for that choice. First, if one assumes that there are at least two investors who offer loan contracts and each entrepreneur applies for her most preferred one, as in the screening model of Rothschild and Stiglitz (1976), one quickly runs into problems of existence of pure strategy equilibrium that makes the analysis tedious. Furthermore, the screening model describes well the functioning of insurance markets but, perhaps, does not describe well the functioning of credit markets. In the latter, one observes entrepreneurs who are willing to undertake a venture, after having built a business plan, to apply for a loan contract to an investor, who decides whether to accept or reject the application. ${ }^{4}$

The remainder of the paper is organised as follows: In Section 2, I describe the economy, I characterise the first-best contracts, and I define a perfect Bayesian equilibrium of the signalling game and when an equilibrium passes the intuitive criterion. In Section 3, I show that the only PBE that passes the intuitive criterion is the least-costly separating equilibrium. I examine the impact of taxation on the equilibrium contracts. Lastly, I show that taxes can create Pareto improvements. In Section 4, I provide policy implications.

\section{THE MODEL}

- Entrepreneurs, Investors and Contracts. There is a continuum of mass one of entrepreneurs. An entrepreneur can be of type $i=1,2$. A set of measure $\lambda_{i}$ is of type $i$. The type of an entrepreneur is her private information. Entrepreneurs own risky projects. The project succeeds or fails but the marginal return is different for the different types. Let

\footnotetext{
${ }^{4} \mathrm{~A}$ model that might be even closer to how trade realises in credit markets is the one in which an entrepreneur applies for an amount of loan to several investors simultaneously with each one selecting the interest rate if the latter decides in principle with the application. The equilibrium set of this game is payoff equivalent to the one I examine in this paper, the latter being simpler since it does not need to model explicitly competition among investors.
} 
$\tilde{z}_{i}=\left(z_{i}, 0\right)$ denote a random variable associated with type $i$, where $z_{1} \neq z_{2}$. By investing $x$ dollars an entrepreneur can realise $\tilde{z}_{i} h(x)$ dollars. ${ }^{5}$ Uncertainty is purely idiosyncratic. I assume that $h(x)$ satisfies standard neo-classical properties such as $h(0)=0, h^{\prime}(x)>0$, $h^{\prime \prime}(x)<0$ and the Inada conditions $\lim _{X \rightarrow 0} h^{\prime}(X)=\infty, \lim _{X \rightarrow \infty} h^{\prime}(X)=0$. Even though they are not necessary and the results remain unaltered without them, the Inada conditions are sufficient to guarantee interior solutions and therefore greatly simplify the analysis and results. ${ }^{6}$ Let $p_{i}$ denote the probability that $z_{i}$ realises. I assume that $p_{1}<p_{2}$ and $p_{1} z_{1}<p_{2} z_{2}$. The project of an entrepreneur of type- 1 has a lower probability to succeed and lower expected return than this of type- 2 for the same amount of initial investment.

For simplicity, I assume that entrepreneurs have no initial funds. To invest, they need to borrow from a wealthy investor in exchange for a share of the returns of the project. Trade takes place through loan contracts. A loan contract takes the following simplistic form: $c=(x, s, f) \in \mathbb{R}_{+}^{3}$, where $x$ is the amount of loan, $s$ is a transfer from the entrepreneur to the investor in case of success and $f$ is a transfer from the entrepreneur to the investor in case of failure. Given the simplicity in the returns of the project, there is no loss of generality in assuming such simplistic contracts. Note that, rather realistically, I only allow transfers from an entrepreneur to the investor after the realisation of uncertainty and not vice versa. Denote the payoff of type $i$ by contract $c$ as $U_{i}(c)=p_{i}\left[z_{i} h(x)-s\right]+\left(1-p_{i}\right)[-f]$ and the profit accrued to the investor as $\pi_{i}(c)=-x+p_{i} s+\left(1-p_{i}\right) f$. Note that the marginal rate of substitution of type $i$ of $x$ to $s$ is $z_{i} h^{\prime}(x)$ and given that $z_{1} \neq z_{2}$, the single-crossing property holds.

First-Best. As a benchmark case, let us characterise the first-best loan contracts without reference to any game.

PROPOSITION 1: The first-best loan contracts under perfect information $\left(c_{1}^{F B}, c_{2}^{F B}\right)$ are characterised by:

$$
\begin{aligned}
& h^{\prime}\left(x_{i}^{F B}\right)=\frac{1}{p_{i} z_{i}} \\
& s_{i}^{F B}=\frac{x_{i}^{F B}}{p_{i}}, \quad f_{i}^{F B}=0
\end{aligned}
$$

PROOF: : To characterise the first-best contract of type $i$, one needs to solve the following maximisation program: $\max _{c}\left\{U_{i}(c): \pi_{i}(c) \geq 0\right\}$. It is rather straightforward to see that

\footnotetext{
${ }^{5}$ The results do not extend to environments in which projects require a fixed investment unless entrepreneurs are strictly risk-averse. The environment then becomes very similar to the insurance environment.

${ }^{6}$ The results hold even when technologies are linear. In that case, however, one needs to assume that there is a bound in how much entrepreneurs can invest to guarantee a finite solution. In that model, the equilibrium is characterised either by corner solutions in which either entrepreneurs of low-quality projects invest at the maximum and entrepreneurs of high-quality projects under-invest (if $z_{1}>z_{2}$ ), or, both types of entrepreneurs invest at the maximum and there is pooling (if $z_{1}<z_{2}$ ). Imposing strictly concave technologies and the Inada conditions make the results "smooth".
} 
the constraint should bind at the optimum. Given that I have restricted the set of feasible contracts to positive transfers from the entrepreneur to the investor, $f_{i}^{F B}=0$ for every $i$. The maximisation program is equivalent to: $\max _{x} p_{i} z_{i} h(x)-x$. Let $g_{i}(x)=p_{i} z_{i} h(x)-x$. Because $h(x)$ is twice continuously differentiable, $g_{i}(x)$ is also twice continuously differentiable with $g_{i}^{\prime}(x)=p_{i} z_{i} g^{\prime}(x)-1$ and $g_{i}^{\prime \prime}(x)=p_{i} z_{i} h^{\prime \prime}(x)$. Recall that $h^{\prime \prime}(x)<0$, which means that $g^{\prime \prime}(x)<0$ and therefore $g_{i}(x)$ is strictly concave. The necessary and sufficient condition for the (unique) global maximum is $g_{i}^{\prime}\left(x_{i}^{F B}\right)=0$ or $h^{\prime}\left(x_{i}^{F B}\right)=\frac{1}{p_{i} z_{i}}$. Because $\lim _{x \rightarrow 0} g_{i}^{\prime}(x)=\infty$ and $\lim _{x \rightarrow \infty} g_{i}^{\prime}(x)=-1$ (from the Inada conditions) we have that $0<x_{i}^{F B}<\infty$. Q.E.D.

In the first-best contracts, the investor makes zero profits on every contract and each type extracts all the surplus conditional on her type. ${ }^{7}$ Because $p_{1}<p_{2}$ and $p_{1} z_{1}<p_{2} z_{2}$, the first-best contracts are distinct for each type and, as expected, entrepreneurs of type-2 invest more than entrepreneurs of type-1.

Signaling Game and Equilibrium. Let $c_{i}$ denote a pure action for type $i$. For every contract observed, the investor updates his beliefs about the type of the entrepreneur. Let $\mu_{i}: \mathbb{R}_{+}^{3} \rightarrow[0,1]$ for $i=1,2$ denote a system of beliefs with $\sum_{i=1,2} \mu_{i}(c)=1$. A decision (strategy) for the investor is denoted as $d: \mathbb{R}_{+}^{3} \rightarrow\{0,1\}$, where $d=0$ is rejection of a contract and $d=1$ is acceptance. I am interested in the perfect Bayesian equilibria (PBE) of this signaling game and especially those that pass the intuitive criterion of Cho and Kreps (1987).

PERFECT BAYESIAN EQUILIBRIUM: A (pure strategy) PBE is a profile of strategies and a system of beliefs $\left(\left(\bar{c}_{i}\right)_{i=1,2}, \bar{d},\left(\bar{\mu}_{i}\right)_{i=1,2}\right)$ such that:

$$
\begin{aligned}
& \bar{c}_{i} \in \underset{c}{\arg \max } \bar{d}(c) U_{i}(c) \forall i=1,2 \\
& \bar{d}(c)= \begin{cases}1, & \text { if } \sum_{i=1,2} \bar{\mu}_{i}(c) \pi_{i}(c) \geq 0 \\
0, & \text { otherwise }\end{cases} \\
& \bar{\mu}_{i}(c)=\left\{\begin{array}{ll}
1, & \text { if } \bar{c}_{i}=c, \bar{c}_{-i} \neq c \\
\lambda_{i}, & \text { if } \bar{c}_{i}=\bar{c}_{-i}=c \\
u \in[0,1], & \text { if } \bar{c}_{i} \neq c, \bar{c}_{-i} \neq c \\
0, & \text { if } \bar{c}_{i} \neq c, \bar{c}_{-i}=c
\end{array} \quad \forall i=1,2\right. \\
& \sum_{i} \bar{\mu}_{i}(c)=1 \quad \forall \quad c \in \mathbb{R}_{+}^{3}
\end{aligned}
$$

${ }^{7}$ Note that these contracts maximise the payoff of both entrepreneurs subject to the investor's break-even condition. Evidently, by keeping $x_{i}^{F B}$ fixed and increasing $s_{i}^{F B}$ one can recover the whole Pareto frontier. I focus on this particular point of the Pareto frontier because there is a link with the equilibrium contracts under imperfect information. See Proposition 2. 
(2.3) says that the strategy of every type needs to be the best response to the strategy of the investor. (2.4) claims that the strategy of the investor needs to be sequentially rational based on his beliefs about the type of the entrepreneur when he sees a loan contract proposal. In particular, the investor accepts a proposal as long as the expected profit (given his belief assessment) is positive. Lastly, (2.5) states that beliefs need to be consistent in equilibrium with the players' equilibrium strategies. (2.6) states that beliefs sum up to one. Note that for any contract off-the-equilibrium path, beliefs are arbitrarily determined to support the equilibrium strategies. As it is known, this arbitrariness is responsible for the sustainment of a continuum of equilibria. Many of these are due to "unreasonable" beliefs, which leads us to examine those PBE that pass the intuitive criterion of Cho and Kreps (1987). A formal definition follows: that:

THE INTUITIVE CRITERION: If for a PBE $\left(\left(\bar{c}_{i}\right)_{i=1,2}, \bar{d},\left(\bar{\mu}_{i}\right)_{i=1,2}\right)$, there exists $c \in \mathbb{R}_{+}^{3}$ such

1. $U_{i}(c)>U_{i}\left(\bar{c}_{i}\right)$

2. $U_{-i}(c)<U_{-i}\left(\bar{c}_{-i}\right)$

3. $\pi_{i}(c) \geq 0$

4. $\bar{d}(c)=0$

then $\left(\left(\bar{c}_{i}\right)_{i=1,2}, \bar{d},\left(\bar{\mu}_{i}\right)_{i=1,2}\right)$ fails to pass the intuitive criterion.

\section{EQUILIBRIA}

Pre-Tax Equilibria. Now consider the case of imperfect information. The set of PBE of the signaling game includes: (i) pooling equilibria in which both types apply for the same contract and the investor makes non-negative profits on average, and, (ii) separating equilibria in which each type proposes a distinct contract, the investor makes a non-negative profit for each one of them and each type has no incentive to misrepresent her type. The following proposition summarises the properties of the set of PBE.

PROPOSITION 2: The following are true:

1. $\left(\left(\bar{c}_{i}\right)_{i=1,2}, \bar{d},\left(\bar{\mu}_{i}\right)_{i=1,2}\right)$ is a separating $P B E$, if and only if:

(i) $\bar{c}_{1} \neq \bar{c}_{2}$

(ii) $\bar{c}_{1}=c_{1}^{F B}$

(iii) $U_{2}\left(\bar{c}_{2}\right) \geq \max \left\{0, U_{2}\left(c_{1}^{F B}\right)\right\}$

(iv) $U_{1}\left(\bar{c}_{1}\right) \geq U_{1}\left(\bar{c}_{2}\right)$

(v) $\pi_{2}\left(\bar{c}_{2}\right) \geq 0$

2. $\left((\bar{c}, \bar{c}), \bar{d},\left(\bar{\mu}_{i}\right)_{i=1,2}\right)$ is a pooling PBE, if and only if: 
(i) $U_{1}(\bar{c}) \geq U_{1}\left(c_{1}^{F B}\right)$

(ii) $U_{2}\left(\bar{c}_{2}\right) \geq \max \left\{0, U_{2}\left(c_{1}^{F B}\right)\right\}$

(iii) $U_{2}(\bar{c}) \geq \max \left\{0, U_{2}\left(c_{1}^{F B}\right)\right\}$

(iv) $\sum_{i} \lambda_{i} \pi_{i}(\bar{c}) \geq 0$.

PROOF: I first prove the only if part of (1). (i) follows from the definition of a separating equilibrium. For (ii), suppose that there exists a separating equilibrium $\left(\left(\bar{c}_{i}\right)_{i=1,2}, \bar{d},\left(\bar{\mu}_{i}\right)_{i=1,2}\right)$ such that $U_{1}\left(\bar{c}_{1}\right)<U_{1}\left(c_{1}^{F B}\right)$. By the definition of PBE for every $c$ either $U_{1}(c)<U_{1}\left(\bar{c}_{1}\right)$ or $\bar{d}(c)=0$. Let $\tilde{c}=\left(x_{1}^{F B}, x_{1}^{F B} / p_{1}+\varepsilon, 0\right)$. Note that $\pi_{1}\left(x_{1}^{F B}, x_{1}^{F B} / p_{1}+\varepsilon, 0\right)>0$ and hence $\pi_{2}\left(x_{1}^{F B}, x_{1}^{F B} / p_{1}+\varepsilon, 0\right)>0$ given that type-2 has a higher probability to succeed. Therefore, regardless the belief of the investor, from $(2.4), \bar{d}(\tilde{c})=1$, otherwise the equilibrium fails to be sequentially rational. This, nevertheless, means that $U_{1}(\bar{c})=U_{1}\left(c_{1}^{F B}\right)-p_{1} \varepsilon$, which for $\varepsilon$ arbitrarily small is greater than $U_{1}\left(\bar{c}_{1}\right)$. This contradicts that for every $c$ either $U_{1}(c)<U_{1}\left(\bar{c}_{1}\right)$ or $\bar{d}(c)=0$. A similar argument establishes (iii). (iv) and (v) are immediate consequences of the definition of a separating equilibrium and hence they do not require a formal proof.

To prove the if part, let (i)-(v) hold simultaneously and moreover: (a) $\bar{\mu}_{1}\left(c_{1}^{F B}\right)=1$, $\bar{\mu}_{2}\left(\bar{c}_{2}\right)=1$ and $\bar{\mu}_{1}(c)=1, \bar{\mu}_{2}(c)=0$ for every $c \neq c_{1}^{F B}$ or $c \neq \bar{c}_{2}$, and, (b) $\bar{d}(c)=1$ for every $c$ such that $U_{1}(c) \leq U_{1}\left(c_{1}^{F B}\right)$ or $c=\bar{c}_{2}$, and $\bar{d}(c)=0$ otherwise. Based on the strategy of the investor, no type has an incentive to apply for a loan contract different than the one she already applies for. This is because for every contract that improves the payoff of any of the types, the investor rejects the application. Furthermore, the strategy of the investor is sequentially rational given his beliefs. Lastly, beliefs are updated by Bayes rule on the equilibrium path and are arbitrarily determined off the equilibrium path in accordance to the definition of equilibrium.

The argument for the only if part of parts (i) and (ii) of (2) is the same as the one given for a separating equilibrium. (iii) is an immediate consequence of the definition of a pooling equilibrium so it does not require a formal proof. The argument for the if part is also similar to the one given above for the separating equilibrium and, therefore, is also omitted. Q.E.D.

The indeterminacy highlighted in Proposition 2 is familiar from signalling games. To pin down the equilibrium set, one needs to restrict the off-the-equilibrium-path beliefs. Therefore, in what follows, I focus on equilibria that pass the intuitive criterion. The "usual suspect" is the least-costly separating PBE. In this equilibrium, type-1 proposes her first-best contract and type- 2 the contract that breaks even and maximises her payoff within the contracts that are weakly not preferred by type-1 over the latter's firstbest contract. In fact, as I formally state in the following proposition, this is the only PBE that passes the intuitive criterion.

PROPOSITION 3. A PBE $\left(\left(\bar{c}_{i}\right)_{i=1,2}, \bar{d},\left(\bar{\mu}_{i}\right)_{i=1,2}\right)$ passes the intuitive criterion if and only if $\bar{c}_{1}=c_{1}^{F B}$ and $\bar{c}_{2}=c_{2}^{n o t a x}$, where $c_{2}^{n o t a x} \in \arg \max _{c}\left\{U_{2}(c): \pi_{2}(c)=0, U_{1}\left(c_{1}^{F B}\right) \geq U_{1}(c)\right\}$. If $U_{1}\left(c_{1}^{F B}\right)=U_{1}\left(c_{2}^{\text {notax }}\right)$ and $z_{1}>z_{2}$, then $x_{2}^{\text {no tax }}<x_{2}^{F B}$. If $U_{1}\left(c_{1}^{F B}\right)=U_{1}\left(c_{2}^{\text {no tax }}\right)$ and $z_{1}<z_{2}$, then 
$x_{2}^{\text {no } \operatorname{tax}}>x_{2}^{F B}$.

PROOF: Sufficiency: Let the PBE $\left(\left(\bar{c}_{i}\right)_{i=1,2}, \bar{d},\left(\bar{\mu}_{i}\right)_{i=1,2}\right)$ such that: (a) $\bar{c}_{1}=c_{1}^{F B}$ and $\bar{c}_{2}=$ $c_{2}^{\text {no tax }},(\mathrm{b}) \bar{d}(c)=1$ for every $c$ such that $U_{1}(c) \leq U_{1}\left(c_{1}^{F B}\right)$ or $U_{2}(c) \leq U_{2}\left(c_{2}^{\text {no tax }}\right)$, and $\bar{d}(c)=0$ otherwise, (c) $\bar{\mu}_{1}\left(c_{1}^{F B}\right)=\bar{\mu}_{2}\left(c_{2}^{\text {no tax }}\right)=1$ and $\bar{\mu}_{1}(c)=1, \bar{\mu}_{2}(c)=0$ for every $c$ such that $U_{1}(c) \geq U_{1}\left(c_{1}^{F B}\right)$ and $U_{2}(c)<U_{2}\left(c_{2}^{\text {notax }}\right)$ and $\bar{\mu}_{1}(c)=0, \mu_{2}(c)=1$ for every $c$ such that $U_{1}(c)<U_{1}\left(c_{1}^{F B}\right)$ and $U_{2}(c) \geq U_{2}\left(c_{2}^{\text {notax }}\right)$. By definition, for every $c$ such that $U_{2}(c)>$ $U_{2}\left(c_{2}^{\text {no tax }}\right)$ and $U_{1}(c)<U_{1}\left(c_{1}^{F B}\right), \pi_{2}(c)<0$ and for every $c$ such that $U_{1}(c)>U_{1}\left(c_{1}^{F B}\right)$, $\pi_{1}(c)<0$. Hence, this PBE satisfies the intuitive criterion.

Necessity: Consider a pooling PBE $\left((\bar{c}, \bar{c}), \bar{d},\left(\bar{\mu}_{i}\right)_{i=1,2}\right)$ such that $U_{1}(\bar{c})>U_{1}\left(c_{1}^{F B}\right), \pi_{1}(\bar{c})<$ $0, \pi_{i}(\bar{c})>0$ and $\sum_{i} \lambda_{i} \pi_{i}(\bar{c}) \geq 0$. In this PBE, for every $c$ such that $U_{2}(c) \geq U_{2}(\bar{c}), \bar{d}(c)=0$. Nonetheless, due to the single-crossing property, there exists $\tilde{c}$ such that $U_{1}(\tilde{c})<U_{1}(\bar{c})$, $U_{2}(\tilde{c})>U_{2}(\bar{c})$ and $\pi_{2}(\tilde{c})>0$ which means that this, or any other pooling PBE, does not pass the intuitive criterion. A similar reasoning establishes the result for any separating equilibrium where $\bar{c}_{2} \neq c_{2}^{\text {no tax }}$.

To complete the proof, suppose that the incentive constraint binds. Let $w(x)=z_{1} h(x)-$ $\frac{x}{p_{2}}-\left[z_{1} h\left(x_{1}^{F B}\right)-\frac{x_{1}^{F B}}{p_{1}}\right] . w(x)$ is a continuously differentiable and strictly concave function and therefore attains a global maximum. Note that $w\left(x_{1}^{F B}\right)=x_{1}^{F B}\left(1 / p_{2}-1 / p_{1}\right)>0$ and $w(0)=-\left[z_{1} h\left(x_{1}^{F B}\right)-x_{1}^{F B} / p_{1}\right]<0$. Because $w(x)$ is strictly increasing in the interval $\left[0, x_{1}^{F B}\right]$, there exists exactly one $\bar{x} \in\left[0, x_{1}^{F B}\right]$ such that $w(\bar{x})=0$. Note now the following: $\lim _{x \rightarrow \infty} w(x)=\lim _{x \rightarrow \infty}\left(z_{1} h(x)-\frac{x}{p_{2}}\right)-\left[z_{1} f\left(x_{1}^{F B}\right)-\frac{x_{1}^{F B}}{p_{1}}\right]=\lim _{x \rightarrow \infty} \frac{x}{p_{2}}\left(\frac{z_{1} h(x)}{\frac{x}{p_{2}}}-1\right)-$ $\left[z_{1} f\left(x_{1}^{F B}\right)-\frac{x_{1}^{F B}}{p_{1}}\right]=\lim _{x \rightarrow \infty} \frac{x}{p_{2}} \times \lim _{x \rightarrow \infty}\left(\frac{z_{1} h(x)}{\frac{x}{p_{2}}}-1\right)-\left[z_{1} f\left(x_{1}^{F B}\right)-\frac{x_{1}^{F B}}{p_{1}}\right]=\lim _{x \rightarrow \infty} \frac{z_{1} h^{\prime}(x)}{\frac{1}{p_{2}}}-$ $\left[z_{1} f\left(x_{1}^{F B}\right)-\frac{x_{1}^{F B}}{p_{1}}\right]=-\left[z_{1} f\left(x_{1}^{F B}\right)-\frac{x_{1}^{F B}}{p_{1}}\right]<0$, with the last equality following from the Inada conditions. Because $w(x)$ is strictly increasing in the interval $\left[x_{1}^{F B}, \infty\right]$, there exists exactly one $\overline{\bar{x}} \in\left[x_{1}^{F B}, \infty\right]$ such that $w(\overline{\bar{x}})=0$. Let us now compare the payoffs of type-2 from $\bar{x}$ and $\overline{\bar{x}}$. We know that $w(\bar{x})=w(\overline{\bar{x}})=0$. Re-writing this: $z_{1} h(\bar{x})-\frac{\bar{x}}{p_{2}}-\left[z_{1} h\left(x_{1}^{F B}\right)-\right.$ $\left.\frac{x_{1}^{F B}}{p_{1}}\right]=z_{1} h(\overline{\bar{x}})-\frac{\overline{\bar{x}}}{p_{2}}-\left[z_{1} h\left(x_{1}^{F B}\right)-\frac{x_{1}^{F B}}{p_{1}}\right]=0$. Rearranging this: $h(\bar{x})-h(\overline{\bar{x}})=\frac{\bar{x}-\overline{\bar{x}}}{p_{2}} \cdot \frac{1}{z_{1}}$, or $z_{2}[h(\bar{x})-h(\overline{\bar{x}})]=\frac{\bar{x}-\overline{\bar{x}}}{p_{2}} \cdot \frac{z_{2}}{z_{1}}$, or $z_{2}[h(\bar{x})-h(\overline{\bar{x}})]-\frac{\bar{x}-\overline{\bar{x}}}{p_{2}}=\frac{\bar{x}-\overline{\bar{x}}}{p_{2}} \cdot\left(\frac{z_{2}}{z_{1}}-1\right)$. If $z_{1}>z_{2}$, then $z_{2}[h(\bar{x})-h(\overline{\bar{x}})]-\frac{\bar{x}-\overline{\bar{x}}}{p_{2}}=\frac{\bar{x}-\overline{\bar{x}}}{p_{2}} \cdot\left(\frac{z_{2}}{z_{1}}-1\right)>0$, which means that $U_{2}\left(\bar{x}, \frac{\bar{x}}{p_{2}}, 0\right)>U_{2}\left(\overline{\bar{x}}, \frac{\overline{\bar{x}}}{p_{2}}, 0\right)$, and hence $x_{2}^{\text {no tax }}=\bar{x}$. On the contrary, if $z_{1}<z_{2}$, then $U_{2}\left(\bar{x}, \frac{\bar{x}}{p_{2}}, 0\right)<U_{2}\left(\overline{\bar{x}}, \frac{\overline{\bar{x}}}{p_{2}}, 0\right)$ and hence $x_{2}^{\text {no tax }}=\overline{\bar{x}}$. Q.E.D.

Note that it might well be true, especially when $z_{2}-z_{1}$ is a large positive number, that the incentive constraint is slack in equilibrium, i.e. $U_{1}\left(c_{1}^{F B}\right)>U_{1}\left(c_{2}^{\text {no tax }}\right)$. In that case, type- 2 can perfectly, and with no cost, signal herself. In what follows, I focus on the more interesting case in which in equilibrium the incentive constraint binds, i.e. $U_{1}\left(c_{1}^{F B}\right)=U_{1}\left(c_{2}^{\text {no tax }}\right){ }^{8}$ Lastly, Proposition 3 states that depending on whether the technology of type- 2 second-order stochastically dominates, i.e. $z_{1}>z_{2}$, or first-order

\footnotetext{
${ }^{8}$ As it was stated in Proposition 3, the zero-profit condition always binds, i.e. $\pi_{2}\left(c_{2}^{\text {no tax }}\right)=0$, and hence the equilibrium contracts are characterised by solving the two constraints simultaneously.
} 
stochastically dominates this of type-1, i.e. $z_{1}<z_{2}$, the equilibrium is characterised by under-investment or over-investment respectively.

The Tax System. I consider a very simplistic redistributive tax system according to which every entrepreneur, regardless her type, pays a fixed tax equal to $t$ in case she succeeds and receives a subsidy equal to $T$ in case she fails. ${ }^{9}$ This tax system is unrealistic in many aspects. Most notably, in reality, entrepreneurs do not pay fixed taxes, i.e. regardless of their income, but most likely the tax system is linear or non-linear. Nonetheless, the use of this tax system greatly simplifies the analysis and results. Furthermore, recall that the main contribution of the paper is to examine under what conditions taxation can create Pareto improvements and how this affects the composition of aggregate investment. Hence, it suffices to consider the simplest possible tax system that achieves this result.

The tax system is ex post budget-balanced. In other words, the government just redistributes wealth ex post without collecting any revenue or providing any resources to entrepreneurs, or without intervening ex ante at the time of contracting. Taxes are nondiscriminatory (or anonymous) in the sense that every type pays the same fixed tax and receives the same fixed subsidy irrespectively of what loan contract she has undertaken. If we let $\hat{p}=\sum_{i} \lambda_{i} p_{i}$, then we consider only taxes such that $\hat{p} t=(1-\hat{p}) T$.

Post-Tax Equilibria. We can now examine the impact of taxation in the equilibrium contracts. As I argued above, even though taxation takes place ex post and contracts are signed ex ante, any subsidy expected to be paid by the government can now be used in the equilibrium contracts. This is enough to influence the behaviour of all entrepreneurs in the market. Indeed, one can show that any subsidy small enough is used in the equilibrium contract by type- 2 . This relaxes the incentive constraint of type- 1 and allows for more investment to flow into the production technology of type-2. Intuitively, this happens because type- 2 is more willing to give up any subsidy in the failure state in order to decrease her payment in the success state, making, that way, her contract less desirable to type-1. This result is formally stated in Proposition 4.

PROPOSITION 4. For any tax-subsidy scheme $(t, T)$ small enough, the only PBE that passes the intuitive criterion is separating and characterised by the pair of contracts $\left(c_{1}^{F B}, c_{2}(t)\right)$, with $c_{2}(t)=\left(x_{2}(t), s_{2}(t), T\right)$ where:

$$
\begin{aligned}
& p_{2} s_{2}(t)+\left(1-p_{2}\right) T=x_{2}(t) \\
& z_{1} h\left(x_{2}(t)\right)-\frac{x_{2}(t)}{p_{2}}=p_{1}\left(z_{1} h\left(x_{1}^{F B}\right)-\frac{x_{1}^{F B}}{p_{1}}\right)+\left(\frac{1-p_{1}}{p_{1}}-\frac{1-p_{2}}{p_{2}}\right) T
\end{aligned}
$$

${ }^{9}$ As pointed out by an associate editor, a tax system that compensates entrepreneurs if they fail might give incentives to them to fail. Note, however, that the results remain unaltered even if the subsidy is paid regardless of the state realised as long as this can be pledged by entrepreneurs as collateral. 
PROOF: Write the payoff of type-1 after taxation as: $U_{1}(c, t)=p_{1}\left[z_{1} h\left(x_{1}\right)-s-t\right]+(1-$ $\left.p_{1}\right)[T-f]=p_{1}\left[z_{1} h(x)-s\right]+\left(1-p_{1}\right)[-f]+\frac{\hat{p}-p_{1}}{1-\hat{p}} t$. Note that this payoff is maximised for $c_{1}^{F B}$ which means that, following the same reasoning as in the proof of Proposition 3 , in any separating equilibrium that passes the intuitive criterion, type- 1 earns in equilibrium at least $U_{1}\left(c_{1}^{F B}, t\right)$. The equilibrium contract of type-2 can be characterised by solving the following optimisation program: $\max _{c}\left\{U_{2}(c, t): \pi_{2}(c) \geq 0, U_{1}\left(c_{1}^{F B}, t\right) \geq U_{1}(c, t), f \leq\right.$ $\left.\frac{\hat{p}}{1-\hat{p}} t\right\}$. Both the profit and the incentive constraints should bind at the optimum otherwise a small decrease in $s$ combined with an small decrease in $x$ satisfies all constraints and increases the payoff of type-2. Let us re-write the two binding constraints: $p_{2} s+\left(1-p_{2}\right) f=$ $x$ and $p_{1}\left[z_{1} h\left(x_{1}^{F B}\right)-t\right]+\left(1-p_{1}\right) T-x_{1}^{F B}=p_{1}\left(z_{1} h(x)-s-t\right)+\left(1-p_{1}\right)(T-f)$. The incentive constraint can be clearly simplified to: $p_{1} z_{1} h\left(x_{1}^{F B}\right)-x_{1}^{F B}=p_{1}\left(z_{1} h(x)-s\right)-\left(1-p_{1}\right) f$. Combining the two constraints we obtain the following: $z_{1} h(x)-\frac{x}{p_{2}}=z_{1} h\left(x_{1}^{F B}\right)-\frac{x_{1}^{F B}}{p_{1}}+$ $\left(\frac{1-p_{1}}{p_{1}}-\frac{1-p_{2}}{p_{2}}\right) f$. Given that $\left(\frac{1-p_{1}}{p_{1}}-\frac{1-p_{2}}{p_{2}}\right) f>0$ for $f>0$, the roots of this equation, denote these as $\left(\bar{x}_{2}, \overline{\bar{x}}_{2}\right)$, are such that $\bar{x}_{2}<\bar{x}<\overline{\bar{x}}_{2}<\overline{\bar{x}}$ for every $f>0$. In fact, $\bar{x}_{2}$ is strictly increasing in $f$ and $\overline{\bar{x}}_{2}$ is strictly decreasing in $f$. The payoff of type- 2 from contracts $\bar{c}_{2}=\left(\bar{x}_{2}, s, f\right)$ and tax $t$ and $\overline{\bar{c}}_{2}=\left(\overline{\bar{x}}_{2}, s, f\right)$ and tax $t$ are respectively:

$$
\begin{aligned}
& p_{2} z_{2} h\left(\bar{x}_{2}\right)-\bar{x}_{2}+\frac{\hat{p}-p_{2}}{1-\hat{p}} t=g_{2}\left(\bar{x}_{2}\right)+\frac{\hat{p}-p_{2}}{1-\hat{p}} t \\
& p_{2} z_{2} h\left(\overline{\bar{x}}_{2}\right)-\overline{\bar{x}}_{2}+\frac{\hat{p}-p_{2}}{1-\hat{p}} t=g_{2}\left(\overline{\bar{x}}_{2}\right)+\frac{\hat{p}-p_{2}}{1-\hat{p}} t
\end{aligned}
$$

From Proposition 1, we know that $g^{\prime}(x)>0$ for every $x<x_{2}^{F B}$ and $g^{\prime}(x)<0$ for every $x>x_{2}^{F B}$. Therefore, in any case, the payoff of type-2 increases with $f$ as long as $\bar{x}_{2}<x_{2}^{F B}<\overline{\bar{x}}_{2}$. The latter implies that $f=T$. When $z_{1}>z_{2}$, then $x_{2}(t)=\bar{x}, x_{2}^{\prime}(t)>0$, and, when $z_{1}<z_{2}$, then $x_{2}(t)=\overline{\bar{x}}, x_{2}^{\prime}(t)<0$. Q.E.D.

As a corollary of Proposition 5, one can examine the effect of taxation on aggregate investment. Denote the economy's aggregate investment as $I(t)$. Following the analysis so far, this is given by the following formula: $I(t)=\lambda x_{2}(t)+(1-\lambda) x_{1}^{F B}$.

COROLLARY 1. $I(t)$ is strictly increasing if $z_{1}>z_{2}$ and strictly decreasing if $z_{1}<z_{2}$.

Pareto Improving Taxation. Now consider the equilibrium payoffs of both types as a function of the tax. Given that $\hat{p} t=(1-\hat{p}) T$, it is clear that type- 1 always benefits from the tax system because she is cross-subsidised. For type-2 there are two opposite effects. On the one hand, there is the negative cross-subsidisation effect. On the other hand, there is the positive effect due to the relaxation of the incentive constraint. The question then is whether the second effect ever dominates the first one. To answer this question, consider the equilibrium payoff of type- 2 as a function of the tax:

$$
V_{2}(t)=z_{2} h\left(x_{2}(t)\right)-\frac{x_{2}(t)}{p_{2}}+\left(\frac{\left(1-p_{2}\right)}{p_{2}} \frac{\hat{p}}{1-\hat{p}}-1\right) t
$$


In Proposition 5, I show that $V_{2}^{\prime}(0)>0$ for every $\hat{p}>\hat{p}^{\text {min }}$, for some $p_{1}<\hat{p}^{\text {min }}<p_{2}$. This means that there is a threshold value in $\hat{p}$ above which positive taxes have a positive impact on the payoff of type-2. Proposition 5 is one of the main results of the paper.

Proposition 5. $V_{2}^{\prime}(0)>0$ for any $\hat{p} \in\left(\hat{p}^{m i n}, p_{2}\right]$, for some $\hat{p}^{\text {min }} \in\left(p_{1}, p_{2}\right)$.

ProOF: Let $V_{2}(t)$ be defined as in (3.3). Because $h(x)$ is continuous and the first and second derivatives exist and they are continuous for any $x>0$, and $x_{2}(t)$ is also continuous and differentiable, $V_{2}(t)$ is also continuous and differentiable. Denote as $V_{2}^{\prime}(t)$ the first derivative of $V_{2}(t)$. Then: $V_{2}^{\prime}(t)=\left(z_{2} f^{\prime}\left(x_{2}(t)\right)-\frac{1}{p_{2}}\right) \cdot x_{2}^{\prime}(t)+\left(\frac{1-p_{2}}{p_{2}} \frac{\hat{p}}{1-\hat{p}}-1\right)$. $V_{2}^{\prime}(0)=\left(z_{2} f^{\prime}\left(x_{2}(0)\right)-\frac{1}{p_{2}}\right)\left(x_{2}\right)^{\prime}(0)+\left(\frac{1-p_{2}}{p_{2}} \frac{\hat{p}}{1-\hat{p}}-1\right)$. Since $z_{2} f^{\prime}\left(x_{2}(0)\right)-\frac{1}{p_{2}}$ and $\left(x_{2}\right)^{\prime}(0)$ are either both strictly positive when $z_{1}>z_{2}$, or, both strictly negative when $z_{1}<z_{2}$, their product is strictly positive. $\left(\frac{1-p_{2}}{p_{2}} \frac{\hat{p}}{1-\hat{p}}-1\right)$ is strictly negative for any $\hat{p}<p_{2}$. Therefore, there exists some $\hat{p}^{\text {min }}<p_{2}$ such that $V_{2}^{\prime}(0)>0$ for any $\hat{p} \in\left(\hat{p}^{\text {min }}, p_{2}\right)$. Q.E.D.

\section{CONCLUSION}

In this paper, I studied a credit market with adverse selection. Privately informed entrepreneurs with risky, variable-investment projects had to borrow from a wealthy investor. Projects differed on their expected returns. I analysed the equilibria of a signalling game, in which each entrepreneur proposed a loan contract to the investor who had to accept or reject. I showed that in the least-costly separating equilibrium, entrepreneurs of high-quality projects might over- or under-invest compared to the social optimum to signal their type. Afterwards, I studied the effect of a tax-subsidy scheme on aggregate investment and welfare. I showed that when entrepreneurs are allowed to use the subsidy they receive from the government on the loan contract, then aggregate investment might be either strictly increasing or strictly decreasing on the tax. Furthermore, for some parameter values both types benefit from the tax scheme.

At least three policy implications are emerging from the analysis. First, as I showed in Proposition 5, taxes create a Pareto improvement if and only if the share of high-quality projects in the market is relatively high. If we accept that during booms high-quality projects outnumber low-quality ones, then an implication of this result is that Pareto improvements might be only possible in booms. On the contrary, during busts the government might be unable to increase welfare and hence, by increasing taxation, welfare decreases. Therefore, during busts, it might be better to reduce taxes.

Second, due to Corollary 1 and Proposition 5, aggregate investment might contract when taxes increase but still welfare might increase. ${ }^{10}$ An increase in taxes brings the economy closer to the first-best that entails a lower level of investment but higher welfare. An implication of this result is that contraction of investment is not necessarily an unfortunate event. In some cases, as it was the case before the global financial crisis of 2007, investment might be so abundant that the government decrease it, through taxation, and increase welfare can by taxation.

\footnotetext{
${ }^{10}$ Recall that this was the case when $z_{1}<z_{2}$
} 
Last, as I argued, a Pareto improvement is possible only if entrepreneurs can pledge any subsidy that they receive from the government as collateral. An implication of this is that when collateral is relatively scarce, then the government by redistributing wealth can increase collateral and hence increase welfare. Note however that, perhaps interestingly, an increase in collateral does not necessarily mean an increase in aggregate investment.

\section{REFERENCES}

[1] AKERLOF, G. The market for "lemons": Quality uncertainty and the market mechanism. The Quarterly Journal of Economics 84, 3 (1970), 488-500.

[2] Asheim, G. B., AND Nilssen, T. Non-discriminating renegotiation in a competitive insurance market. European Economic Review 40, 9 (1996), 1717-1736.

[3] Bisin, A., AND GotTARDI, P. Efficient competitive equilibria with adverse selection. Journal of Political Economy 114, 3 (2006), 485-516.

[4] CHO, I. K., AND KREPS, D. M. Signaling games and stable equilibria. The Quarterly Journal of Economics 102, 2 (1987), 179-221.

[5] CROCKeR, K. J., AND SNOW, A. The efficiency of competitive equilibria in insurance markets with asymmetric information. Journal of Public Economics 26, 2 (1985), 207219.

[6] CROCKer, K. J., AND SNOW, A. A simple tax structure for competitive equilibrium and redistribution in insurance markets with asymmetric information. Southern Economic Journal 51, 4 (1985), 1142-1150.

[7] DAHLbY, B. Adverse selection and pareto improvements through compulsory insurance. Public Choice 37, 3 (1981), 547-558.

[8] De MezA, D., And WebB, D. Too much investment: A problem of asymmetric information. Quarterly Journal of Economics 102, 2 (1987), 281-292.

[9] Diasakos, T., And Koufopoulos, K. Efficient Nash equilibrium under adverse selection. Working paper, SSRN, 2011.

[10] Dosis, A. An efficient mechanism for competitive markets with adverse selection. Working paper, ESSEC Business School, 2015.

[11] GhataK, M., Morelli, M., AND SJÖStrÖM, T. Entrepreneurial talent, occupational choice, and trickle up policies. Journal of Economic Theory 137, 1 (2007), 27-48.

[12] INNES, R. Investment and government intervention in credit markets when there is asymmetric information. Journal of Public Economics 46, 3 (1991), 347-381.

[13] MARTin, A. A model of collateral, investment, and adverse selection. Journal of Economic Theory 144, 4 (2009), 1572-1588. 
[14] MARTiN, A. Adverse selection, credit, and efficiency: the case of the missing market. Tech. rep., 2011.

[15] Mimra, W., AND Wambach, A. A game-theoretic foundation for the wilson equilibrium in competitive insurance markets with adverse selection. Working paper, CESifo Series No. 3412, 2011.

[16] MIYAZAKI, H. The rat race and internal labor markets. The Bell Journal of Economics 8,2 (1977), 394-418.

[17] NetZer, N., AND SCHEUER, F. A game theoretic foundation of competitive equilibria with adverse selection. International Economic Review 55, 2 (2014), 399-422.

[18] PICARD, P. Participating insurance contracts and the Rothschild-Stiglitz equilibrium puzzle. The Geneva Risk and Insurance Review 39, 2 (2014), 153-175.

[19] RothSCHILD, M., AND STIGLiTZ, J. Equilibrium in competitive insurance markets: An essay on the economics of imperfect information. The Quarterly Journal of Economics 90, 4 (1976), 629-649.

[20] ScheueR, F. Adverse selection in credit markets and regressive profit taxation. Journal of Economic Theory 148, 4 (2013), 1333-1360.

[21] SPENCE, M. Job market signaling. The Quarterly Journal of Economics 87, 3 (1973), 355-374.

[22] SPENCE, M. Product differentiation and performance in insurance markets. Journal of Public Economics 10, 3 (1978), 427-447.

[23] Stiglitz, J., AND Weiss, A. Credit rationing in markets with imperfect information. American economic review 71, 3 (1981), 393-410.

[24] WiLsON, C. A model of insurance markets with incomplete information. Journal of Economic Theory 16, 2 (1977), 167-207. 


\section{PARIS}

ESSEC Business School

3, avenue Bernard-Hirsch

CS 50105 Cergy

95021 Cergy-Pontoise Cedex

France

Tél. + $33(0) 134433000$

www.essec.fr
ESSEC Executive Education

CNIT BP 230

92053 Paris-La Défense

France

Tél. + $33(0) 146924900$

www.executive-education.essec.fr
ESSEC Asia Pacific

2 One-North Gateway

Singapore 138502

Tél. +65 68849780

www.essec.edu/asia

\section{SINGAPOUR}

Contact :

Centre de Recherche

+33 (0)134433091

research.center@essec.fr

ISSN 1291-9616 